Review

\title{
Health information prescription system for non communicable diseases: a systematic review and thematic analysis
}

\author{
Abdolahad Nabiolahi, Shahram Sedghi, Rokhsareh Aghili, Leila Nemati-Anaraki \\ Iran University of Medical Sciences, Tehran, Iran
}

Received 7 April 2020, Revised 20 july 2020, Accepted 6 October 2020

(C) 2020, Nabiolahi A., Sedghi S., Aghili R, Nemati-Anaraki L.

(C) 2020, Russian Open Medical Journal

\begin{abstract}
Objective - Prescribing health information is very important to empower informed patients. The goal of present study is to recognize challenges for developing health information prescription on non-communicable diseases.

Material and Methods - Six data bases related to health information prescription were investigated. They included Web of Science, Scopus, PubMed, Google Scholar, Ovid and EMBASE. The investigated studies were published from 2000 to 2019. The language of the articles was English and the access to full text was one of the inclusion criteria. The research was evaluated by Prisma checklist and critical apprising. Different dimensions of health Information prescription system were recognized by thematic analysis.

Results - 54 studies were recognized based on the inclusion criteria. The results showed that there were three main concepts related to primary dimensions of the system in designing health information prescription system: determination of system functional goals, recognition of implementation barriers and recognition of developmental sub-structures. There were 16 subcategories including primary goals for accessibility, the concerns related to patients information confidentiality, individual differences and interests and personalizing the process of information prescription, the lack of integrity in health Information system for providing pattern of health Information system related to diabetic patients.

Conclusion - The goals, implementing barriers and functional substructures of health information prescription system should be recognized in order to improve self-care behaviors of diabetic patients in clinic. It is recommended that the future investigations focus on research gaps in personalizing health information prescription and integration of health information prescription process in health care system.
\end{abstract}

Keywords: health information prescription, diabetic patients, information prescription system.

Cite as Nabiolahi A, Sedghi S, Aghili R, Nemati-Anaraki L. Health Information Prescription System for Non communicable Diseases: A Systematic Review and Thematic Analysis. Russian Open Medical Journal 2020; 9: e0406.

Correspondence to Shahram Sedghi. Phone: +98 (21) 88782919. Fax: +98 (21) 88883334. Email: sedghi.s@iums.ac.ir.

\section{Introduction}

Nowadays, information plays an important role in decision making process in various areas and is considered as a global source of authority [1]. The knowledge of patient with regard to his own health condition can provide sound health-related decisions. Since misinformation hurts the patients and health condition consumers of health system potentially, health information and the process of its prescribing should be taken into consideration. The development of health information prescription system (IPS) can be a proper measure to minimize the mentioned problems [2]. Information prescription is the providing of evidenced-based medical information for an especial patient in a suitable time if that information can help the patient in decisionmaking and behaviour modification. In other words, information prescription is the providing of proper information to the right receiver in a suitable time in order to make sound decision by the patient $[3,4]$. In fact, the goal of health information prescription system is the providing, collecting and presenting the information for the diabetic patients in order to help them to make right health-related decisions [1-3]. Non-communicable diseases are known as the major challenge of health system. Based on the statistical figures of the WHO, non-communicable diseases cause 38 million deaths annually. On the other hand, three fourth of deaths (28 million) are happened in low and middle income countries. According to the WHO's report, diabetes is the fourth agent of mortality with 1.5 deaths annually. Diabetes, cancers, cardiovascular and respiratory diseases cause 82 percent of deaths [5-7]. Since the number of people with chronic diseases have been increased in health care centers, it is necessary to initiate new approaches for involving the clients toward self-care based on personal contribution and accountability. Diabetic patients are recently interested to seek health information, recommendation and support. They are changed into active users with high level of decision-making ability. Information prescription system of diabetic patients provides this opportunity for them and their families to contribute actively in treatment process by having enough knowledge about disease condition, the stages of diagnosis and therapy and the information of the nearest health centers. 
Health Information prescription programs have been taken into consideration in private and governmental sectors of developing countries in order to promote the prevention services and urgent measures by the patients [8-11]. Some of these programs for patients included British Health Care System, California Plan Tree Health Information Center, Health Information Center of American National Cardiovascular Institute and Health Information Center of Washington University Of Medical Sciences [12-14]. Recent studies have emphasized the usage of information prescription system as a reinforcing factor of physician-patient relation [15-17]. The conducted investigations in developing countries have been review articles. They presented the advantages and importance of information therapy $[8,18]$. The contribution of librarians with regard to information therapy was studied in an investigation. Some research has been conducted to study the Feasibility of implementing information therapy and the physicians' viewpoints [19-21]. There were some studies which investigated information prescription system in other settings [22]. The studies personalizing information prescription for diabetes, taking systemic cases into consideration or recognizing the dimensions of health information prescription system based on systematic review approach were not found. The main challenge of this investigation is to recognize the conducted research in according to practical challenges of health information prescription. The present systematic review study recognized major components of health information prescription system related to non-communicable diseases with the focus on diabetes. This was done to identify the main elements of the mentioned system including the identity of disease, its complications, family education, disease terminology, patient consultation with specialists, essential substructures and the major content in designing the system.

\section{Material and Methods}

\section{Search strategy}

The documents related to the subject of study in data bases including EMBASE, Scopus, OVID, WOS, PubMed and Google Scholar were researched from 2000 to 2019 . Research process was started from 2019 October 1st. The researched words included information Prescription System OR Information Prescription Services and the combination of Health Information Prescription, Information therapy, information Services, Info Rx, Rx, Patient Education, Non communicable Disease and Diabetes words.one sample of search strategy in PubMed is as follows:

()(("health information prescription"[Title] OR "info scripts"[Title] OR "information therapy"[Title] OR "Information Prescription"[Title] OR InfoRx [Title] OR Rx[Title] OR "personalized health information"[Title] OR "prescribed information"[Title] OR "information reading prescription"[Title] OR "prescription for reading"[Title] OR "reading on prescription" OR "information prescription system" OR information prescription service*")) NOT DRUG).

\section{Study selection}

Endnote V. 8 produced by Clarivate Analytics was used to organize the titles, abstracts and distinguish the repeated cases [23]. Inclusion criterion included the articles which studied at least one of the present study's goals from 2000 to 2019.The articles which their publication time was out of the defined episode, written by non-English languages or their full text were not accessible were excluded from present investigation.

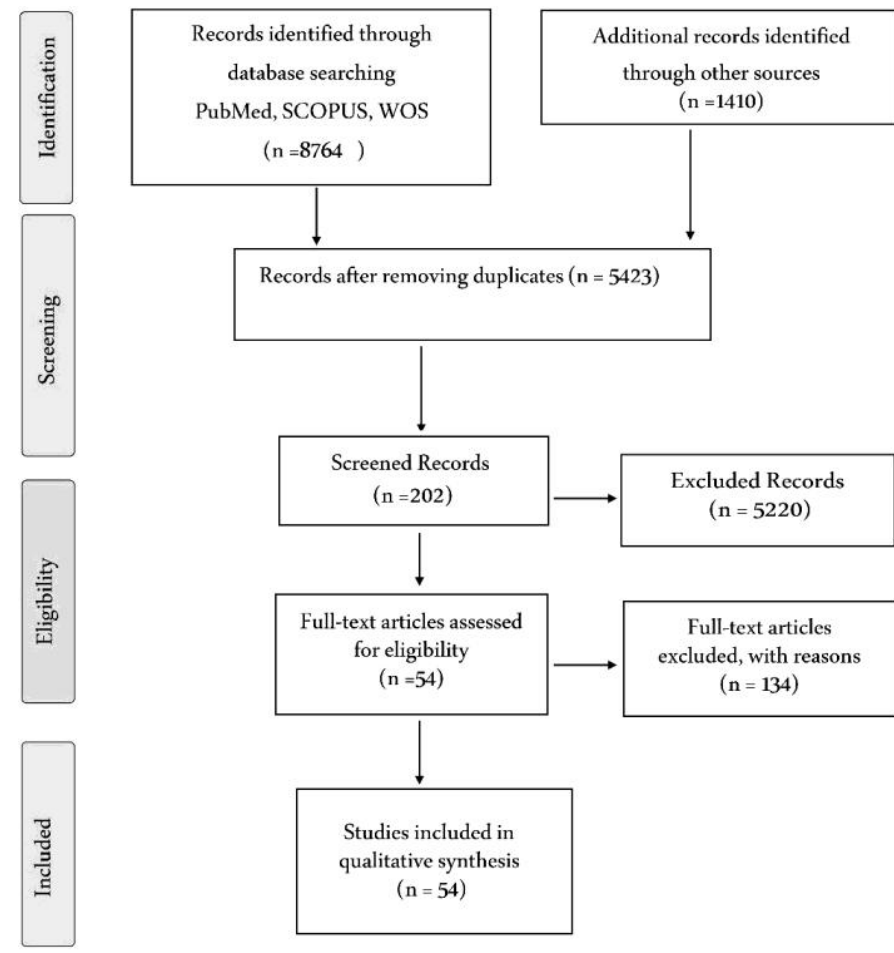

Figure 1. Prisma flow diagram [25]

The research results were evaluated by STROBE Checklist and the high qualified articles were selected [24]. They were assessed by two members of research team. It was tried to select those articles which have studied different dimensions of health information prescription system.

\section{Data synthesis}

Descriptive and content analyses were used to assess the selected articles and textual data. The selected studies were investigated to extract major results including any subjects related to health information prescription system, influencing factors in designing and developing the system, the advantages and drawbacks, implementing barriers of diabetic information prescription system, the data associated to this disease for implementing health information prescription system and present gaps in developing this system and future research. A list of reasons for exclusion is included in Figure 1.

\section{Results}

\section{Descriptive dato}

In present study, 20 quantitative and 7 qualitative studies were reviewed. The summary of the reviewed studies' characteristics is presented in Appendix 1 . It was reported that 9, 5 and 4 quantitative studies used survey, randomized clinical trial, and quasi-experimental methods.

In addition, 4 studies used mixed approach of some different methods simultaneously. Two of these articles used comparative approach. Meanwhile, 4 studies reported the experiences of the programs or the measures related to information prescription.

It was found that 26 studies were conducted in The U.S. with the cooperation of National Medicine Library, Virginia, Vermont, Missouri and Colombia Universities. Nine and one studies were 
done in England and Scotland. Besides, 9 studies were done in Iran in Tabriz, Beheshti and Isfahan Universities of Medical Sciences. The rest of reviewed studies were conducted in Finland, Australia, India, Norway, Canada and Nigeria.

The most attention of researchers in this field of study was seen between 2010 to 2015.The primary ideas were formed in 2002-2003.Different studies investigated various areas of health information prescription including systems' advantages, substructures, developing strategies, mechanisms of accessibility and information delivery, system effectiveness assessment , the status of health electronic records in establishing the system, contribution of librarians and physicians in information prescription program and diabetes modifiers in making the system.

\section{Different dimensions of health information prescription system}

Health Information Prescription System Goals. The goals and function of health information prescription system are presented in various articles. The main goals of health information prescription system included medical services improvement, user's accessibility to credible information, improving patients' knowledge, increasing self-care potentiality and disease management, reinforcing relation between physician and patient, stabilizing the physician role in health information prescription cycle (Table 1).

The Barriers of Establishing Health Information Prescription System. The analysis of the study showed that six agents related to establishing health information prescription system were recognized: confidentiality, individual interests and differences, technology substructures, time limitation, the problems related to information providing and cost (Table 2).

Recognizing of design substructures and development of health information prescription system. The most important developmental substructures of information prescription for noncommunicable Diseases are skilled staff, the strategies for using information and communication technology, essential characteristics of health information resources, health electronic records, the essentialities of system function and fulfilling of possible budget (Table 3).

Table 1. The goals of health information prescription system

\begin{tabular}{|c|c|c|c|}
\hline Concept & Category & Sub Category & Resource/s \\
\hline \multirow{5}{*}{$\begin{array}{l}\text { Determination } \\
\text { of goals of } \\
\text { health } \\
\text { information } \\
\text { prescription } \\
\text { system }\end{array}$} & $\begin{array}{l}\text { Medical services } \\
\text { improvement }\end{array}$ & $\begin{array}{l}\text { Decrease and prevention from medical faults, time saving, high qualified medical care's guarantee, } \\
\text { increase in efficacy costs, increase patients satisfaction, providing extra value. }\end{array}$ & {$[1,10,26-31]$} \\
\hline & $\begin{array}{l}\text { Users accessibility to } \\
\text { credible information }\end{array}$ & $\begin{array}{l}\text { Patients' accessibility to the refined information, accessibility to online and community-based } \\
\text { references, providing information to diabetic patients, tne guarantee of information quality and its } \\
\text { dimensions, patients use of credible reference, physician recommended information by physician. }\end{array}$ & {$[1,7,10,32,33]$} \\
\hline & $\begin{array}{l}\text { Improving patients } \\
\text { knowledge }\end{array}$ & $\begin{array}{l}\text { Increase in patients' special knowledge, increase in patients' perception about disease, reinforcing } \\
\text { tne perception of concepts about disease, better perception of disease condition. }\end{array}$ & {$[27,29,33-36]$} \\
\hline & $\begin{array}{l}\text { Increasing self-care } \\
\text { potentiality and disease } \\
\text { management }\end{array}$ & $\begin{array}{l}\text { Increase in self-care potentiality, non-communicable diseases, self-management, behavior change in } \\
\text { treatment and health behavior, reinforcing health goals, and increase in selfmanagement skill. }\end{array}$ & {$[7,10,34,37-39]$} \\
\hline & $\begin{array}{l}\text { Stabilizing the physician } \\
\text { role in health information } \\
\text { prescription cycle }\end{array}$ & $\begin{array}{l}\text { Stabilizing the physician role in health information prescription cycle, patients' question askingfrom } \\
\text { physician, reinforcing patient-physician relation, attitude change in physician and use of information } \\
\text { prescription. }\end{array}$ & $7,32,34,38,40,41]$ \\
\hline
\end{tabular}

Table 2. The barriers of establishing health information prescription system

\begin{tabular}{|c|c|c|c|}
\hline Concept & Category & Sub Category & Resource/s \\
\hline \multirow{8}{*}{$\begin{array}{l}\text { The barriers of } \\
\text { establishing } \\
\text { health } \\
\text { information } \\
\text { prescription } \\
\text { system }\end{array}$} & Confidentiality & $\begin{array}{l}\text { Lack of assurance about patient's information confidentiality .confidentiality and commitment } \\
\text { affairs, confidentiality between physician and patient, security and patient privacy }\end{array}$ & {$[1,26,42,43]$} \\
\hline & & Variation in society literacy level, lack of patient's tendency to receive information [47], person's & \\
\hline & $\begin{array}{l}\text { Individual differences in } \\
\text { health information } \\
\text { seeking }\end{array}$ & $\begin{array}{l}\text { inability in filtering unsuitable information, different level of people's literacy, physician's reluctance } \\
\text { for adding information prescription as a part of his own professional activities, communication style, } \\
\text { active and inactive health information receiving, patients' inability in using computer [39], } \\
\text { insufficient involvement or patients' contribution in care programs [48]. }\end{array}$ & $\begin{array}{l}{[1,4,26,33,39,42,} \\
44-48]\end{array}$ \\
\hline & Time limitations & Time limitation [47], time limitation in consultation, time limitation in patient-physician interaction. & [47], [49], [42], [43] \\
\hline & Technical barriers & $\begin{array}{l}\text { Lack of integrity in health information system, practical program of communication and information } \\
\text { technology, technical problem in system and information technology, saving space, limited access to } \\
\text { technology in rural areas. }\end{array}$ & {$[27,42,49-51]$} \\
\hline & $\begin{array}{l}\text { Barriers of health } \\
\text { information providing }\end{array}$ & $\begin{array}{l}\text { Quality of information, fulfilment and estimate in criteria of information quality, being multi- } \\
\text { language, physicians concern about precise content. }\end{array}$ & {$[1,43,44,50,52]$} \\
\hline & & Budget limitation, financial barriers for providing and increasing accessibility Jack of interaction & \\
\hline & $\begin{array}{l}\text { Organizational } \\
\text { cooperation }\end{array}$ & $\begin{array}{l}\text { among the organizations for providing the content, The integration in local and state regularities, } \\
\text { the support provided by medical information and information technology units, libraries and } \\
\text { information centers, recognizing the societies, organizations and any other sectors having rich } \\
\text { sources of especial conditions. }\end{array}$ & {$[49,50,52-55]$} \\
\hline
\end{tabular}


Table 3. Recognition of design substructures and development of health information prescription system

\begin{tabular}{|c|c|c|c|}
\hline Concept & Category & Sub Category & Resource/s \\
\hline & $\begin{array}{l}\text { Providing of skilled } \\
\text { staff }\end{array}$ & $\begin{array}{l}\text { Providing of skilled staff, health information specialist, subject and hospital librarians, information } \\
\text { prescription team and the care team members, use of information specialists, recognizing health } \\
\text { prescription physician, medical and information science librarians, using software and hardware } \\
\text { specialists, information technology unit managers, graphic designer. }\end{array}$ & $\begin{array}{c}{[1,26,37,44,50} \\
52,56,57]\end{array}$ \\
\hline & $\begin{array}{l}\text { Strategies for using } \\
\text { information and } \\
\text { communication } \\
\text { technology ( ICT) }\end{array}$ & $\begin{array}{l}\text { Information and communication technology substructures, changing from paper system to diabetic } \\
\text { management systems based on information technology, Accessibility instrument such as } \\
\text { information PADS, sending mechanism and different access and educational module application, } \\
\text { Multimedia formats, Data bases formation, participation strategy for patient's family member in } \\
\text { system, Patient's portal designing, use of Internet and similar devices, information dashboard for } \\
\text { documentation and following blood sugar rate. } \\
\text { Peer patients approach and peer patient's network, the application of congested information } \\
\text { forums, use of integrated educational portal in diabetic patients care program. }\end{array}$ & $\begin{array}{l}{[1,26,33,39,42-} \\
44,48,53,58-68]\end{array}$ \\
\hline & & $\begin{array}{l}\text { Providing health information, information resources fulfillment and content providing, quantity } \\
\text { reinforcement, The quality and fluency of continuous health information with an appropriate } \\
\text { language and systematic production of health information content based on information }\end{array}$ & \\
\hline
\end{tabular}

\section{Designing Essential}

substructures characteristics of

and development health information

of health resources

information

prescription

system

\section{prescription standards, recognition the type of information resource used by diabetic patients, the} content with medical terminology, pharmaceutical information, the information related to the signs, identifying and treatment-being multi- linguistic (English, Persian,...).

Seven-part health information characteristics: decision-focused, evidenced based, reviewed by experts, free from commercial bias, user friendly with simple perceptiveness, references signpost by

The date of revision and Internet reference should be noted. Use of structured clinical guidelines, content relevant to personal characteristics, use of medical sciences publishers/governmental websites and medical associations.

Budget fulfillment, funding for electronic record research and information prescription system, th

Financial fulfilment cost for establishing and staff education, providing budget policies.

$[26,42,43,49,60$

Identity information fulfillment of diabetic patient, health electronic record through the item of ordering information prescription in physician orders profiles and sending it to the librarian, the

Health electronic interaction process with health system through adding practical program of information records prescription with patient's health electronic record system.

Person's assessment modules: person's records, lifestyle, tests results, eye assessment, leg assessment, medicines, diaries, patient's interests

Accessibility and usability of information technology program, reinforcing information sending

mechanisms such as information forms and discussion groups, interactive characteristics for personalizing information, multi-usage and research capability.

Functional requirements of Task function for registering blood sugar and body weight, seekin system physical activity and appointment for the next follow-ups.

Functional challenges: credit assessment of entering and exiting the system and forgetfulness of account number, keeping the user in system or sending message or email.

\section{Discussion}

Designing and developing of health information prescription need to recognize different dimensions of this phenomenon. Present systematic review aims to recognize its major modifiers based on thematic analysis. Since diabetes is multi-faceted, its cares process and information prescription in clinical environment requires a multi-dimensional and multi-disciplinary approach [59]. Therefore, present thematic study categorized the major needs of system development as follows: goals, the substructures of designing and development and the barriers of establishment health information prescription system.

\section{Prioritizing of health information prescription system goals}

It is necessary to set some goals for strategies and essential processes before providing a program or a system. As Anaestad states, Patient-centered electronic systems is known as an opportunity to reinforce the role of patient in the process of care providing and patient-centered case [74]. The health information prescription system of diabetes patients can be included the most important goals of medical care improvement, users accessibility to data resources, improvement in patients' knowledge, reinforcing self-care process and disease management and also reinforcing the relation between patient and physician in the cycle of health information prescription system.

The most important goals and advantages of health prescription system for physicians, patients and different levels of health system have been presented in various studies [26, 33-35, 49].For instance, some of the provided advantages for health system included decreasing in patient education time and time saving, providing better health outcomes, medical errors decrease and improving patient safety, developing the responding capacity through having access to refined information and changing physicians' attitude with regard to health information prescription, reinforcing patient-physician relation and efficacy promotion [7, $10,26,40]$.

Moreover, patients can do higher qualified self-care after the intervention conducted through information prescription. This also can be done to increase patient's knowledge about the disease, its impacts and the factors which affect its treatment [27, 29, 33-36]. 


\section{Recognition of designing and development substructures related to health information prescription system}

It is crucial to identify the most important substructures of the system and do following measures in order to collect them. This is done to develop health information prescription system in especial clinical environments.

\section{The formation of special multi-levels of human forces}

Literature analysis showed that developing substructures of the system requires to use the combination of human forces with multi-specialties such as health information specialist, clinical medical librarian, information prescription team and the member of care team, physicians, nurses and health care staff $[1,18,26$, 52].

This contribution is provided through direct or systematic information prescription for the patient by every one of treatment staff or referral process to the medical librarians and health information specialist. The role of librarians in this process is to bring about the content of health information prescription in accordance with personalized needs of diabetic patient $[27,36,37$, $41,44,56,75]$.

The involvement of technology team members including software and hardware specialists, managers of information technology unit and graphic designers are known as the essential parts of unique and comprehensive system designing [50,57].

Use of information technology and communication for facilitating health information exchange

Use of information technology and communication (ICT) for facilitating health Information exchange between diabetic patients and medical specialists is included in the second dimension of infrastructures. Technology infrastructures can be consisted of providing practical tools or programs for health information prescription used by patients, primary technical resources, Internet, informational networks and so one $[1,26,33,39,42-44$, $48,53,58-68]$. In fact, patient-oriented electronic health services are provided to respond the increasing request for Internet as the source of health information and supply the quality of accessible information. Peer-patient networks capacities, informational forums and social media can be used to provide these services and using informational dashboard has been recommended for documentation and blood sugar follow-up $[50,66,67,76,77]$.

\section{The quality and reliability of system's information content}

Collecting the health information resources is the necessary element of health information prescription system. Information prescription was designed in the form of informational brochures, but electronic information prescription requires digital content to respond urgent needs of diabetic patients. The content of health information have to include medical terminology, pharmaceutical information, signs, diagnostic and therapeutical information and new therapies. This content should be precise, decision-oriented, evidence-based, reviewed by specialists, up-to-date, personalized, provided on time, free from advertisement and also it has to be referenced $[1,7,10,26,36,37,39,44,49,50,53,63,68-71]$.

The authority of information content should be guaranteed by Signposting to references by physicians and mentioning the characteristics of content such as its writer, the date of its revision and its Internet reference $[50,78]$. Moreover, using the necessary standards in providing health content for diabetic patients can lead to achieve patients' trust. Recommended standards for providing information content include MLA, HON code criteria and use of credible websites such as MEDLINE PLUS, Diabetes World Societies and other similar departments. [39, 68, 79]. Another challenge on the basis of content dimension is the conservation of health information content in according to the signs of noncommunicable disease and its complications. This needs to use national or international diseases categorization systems, sinning metadata, digital and standard codes (UMLS, CPT, MESH, SNOMED) by information specialists. It is done to organize qualified information $[10,80]$.

\section{Patient's health electronic record}

The standards of health information prescription system include patient's personal health record as one of the most important elements of this system [81]. It has the capability of collecting and saving patients' informational data and their exchange by different electronic tools or sending informational prescription. Patient's health electronic record provides identity information and the history of diabetic patients. They can facilitate the interaction with health system as a practical information prescription program though adding information prescription order item in the "physician orders" input and sending it to librarian[10, 35].The key modifiers of diabetes management include organizational tools of patient's panel and disease registration system for recognizing high risk population ,clinical indices based on evidence, practicing clinical guidelines in the patient's panel and registry system used by automatic systems[82]

\section{Functional requirements of information prescription system}

Informational systems need to have practical capabilities such as crediting the users' entrance and exit in different episodes, displaying patient's profile in personalized level in the physician's access for prescribing the information, interacting power of information prescription system with other department's systems in order to exchange information by using credible standards [59, $61,71]$.Accessibility and practicability of information technology program, reinforcing mechanisms for sending information such as informational forms and discussion groups, use of visualization for removing verbal barriers are the most important requirements of the system. Meanwhile, the following recommendations are provided to succeed the management of diabetes: blood sugar and body weight monitoring, seeking information about nutrition matters, physical activity and follow-ups for receiving consult [57, $59,61,71,73]$.

\section{The recognition of establishment barriers of health information prescription system}

The major barriers against performing information prescription with regard to non-communicable diseases especially diabetes include confidentiality subject, personal differences, informational needs of users, time limitation, technical obstacles, organizational obstacles and the challenge of information providing. There are some factors which should be tackled before system establishment: lack of assurance feeling with regard to confidentiality of patient's information, the commitment between physician and patients $[1,4,26,33,39,42-49]$, socio-economic 
personal differences, patient incapability in using technology[27, 42, 49-51], time limitation of consult and patient-physician interaction, integrity of health informational system, saving space, information quality and physician concerns about preciseness of informational content(reference) and cooperation of system establishment with regional and organizational [1, 43, 44, 49, 50, 52-55].

\section{Confidentiality}

This subject is regarded significant in all health environments. Lack of assurance feeling with regard to confidentiality of patient's information and the commitment between physician and patients are two instances of confidentiality in health information prescription. Some measures are suggested to do in order to reinforce this subject: the measuring of user's credit while entering to system, reinforcing multi-security layers and providing necessary education about system security to users and managers $[1,26,42,43]$.

\section{Personal differences related to users' information needs}

There are a number of barriers related to this subject against establishment of health information prescription system: the variety of literacy level of population and lack of patient's tendency to receive information from his physician as a part of professional activities and communication style $[1,4,26,33,39$, $42,44-48]$.

The specialists of diabetes and other fields suggest some alternatives to resolve these barriers: use of personalization of health information process in a way that informational product can be adapted to user's preferences in subject, content, display method and information providing style. Information need assessment of users requirements is the inseparable part of health prescription system of non-communicable diseases especially diabetes for recognizing personal differences and patients' interests [83].

\section{Time limitations}

Time limitation of consult and patient-physician interaction is the matter of face to face or group information prescription [1, 10, 26-31]. Health information prescription System (IPS) tries to resolve this problem so that users' access to system from distances, provided information content based on diabetic patients' needs, patients' knowledge and attitude about their own health, saving in patient's time and improvement in care process.

\section{Technical barriers}

The review of articles showed some major barriers which make informational prescription system complicated: lack of integrity of health informational system, practical program of information and communication, technical problems of information technology, system and saving space and limited access to technology in rural regions $[51,84]$.

In conclusion, Designing of information prescription system requires the contribution of multi-disciplinary professional staff especially physicians. Moreover the education of various information prescription users is known as a key factor in promotion of information prescription design. The future research should be focused on the strategies of improving the quality of health information content, integrity of health information prescription system in health services and the assessment of establishing similar systems in medical libraries. This can lead to reinforce the process of contributive care designed for noncommunicable diseases in health system.

\section{Conclusion}

The research was conducted to identify the effective components in prescribing information with the approach of noncommunicable diseases based on thematic analysis and utilization of systematic method. The result of study showed that noncommunicable diseases units for development of information prescription plan and improvement of self-care behaviors of diabetic patients, must consider primary goals, strategies and the barriers against establishing infrastructures of information prescription system.

\section{Limitations}

The articles who's their full text were not available and published in non-English languages were removed from the study despite this fact that some of them owned various characteristics of information prescription system. There was vast restriction in the access to some data bases. This lead to miss a large number of studies which could have been reviewed. Also, the investigations related to bibliotherapy or the similar subjects were not reviewed. Besides, the studies focused on systematic trend or recognition of the agents affecting development have been reviewed. However, it is possible that some theses studies were removed unintentionally.

\section{Funding}

This study was funded by Research and Technology Vice Chancellor of Iran University of Medical Sciences.

\section{Conflicts of Interests}

The authors declare that they have no conflict of interest.

\section{Acknowledgement}

This study is a part of PhD dissertation in Medical Library \& Information Sciences which was certified by Iran University of Medical Sciences with the following ethical code: IUMS/SHMIS_1396-9321623002.

\section{References}

1. Zare Farashbandi F, Yarahmadi A. Information therapy: A new approach with old concept in improvement of chronic diseases. Health Information Management 2015; 12(1): 125-135. Persian. http://him.mui.ac.ir/index.php/him/article/view/1619.

2. Parvizrad P, Mirzaei S. Health related websites evaluation. Health Information Management 2006; 3(1): 5-11. Persian. http://him.mui.ac.ir/index.php/him/article/view/40.

3. Gavgani VZ, Shokraneh F. Information Therapy (Ix) and Information Prescription: A Systematic Review. International Journal of User-Driven Healthcare 2013; 3(2): 9-19. http://doi.org/10.4018/ijudh.2013040102.

4. Lamiraud K, Von Bremen K, Donaldson C. The impact of information on patient preferences in different delivery patterns: A contingent valuation study of prescription versus OTC drugs. Health policy 2009; 93(2-3): 102-110. https://doi.org/10.1016/i.healthpol.2009.05.014. 
5. World Health Organization. Noncommunicable diseases. Geneva: World Health Organization. http://www.who.int/mediacentre/factsheets/fs355/en/.

6. Self care management. Special Issue in Self Care. Gazvin University of Medical Sciences, 2014: 1-4. http://qums.ac.ir/Portal/file/?198713/olom-rangi-80_2.pdf

7. Mettler M, Kemper DW. Information therapy: health education one person at a time. Health Promot Pract 2003; 4(3): 214-217. https://doi.org/10.1177/1524839903004003004.

8. Jerliu N, Burazeri G, Toçi E, Kempen GI, Jongen W, Ramadani N, et al. Social networks, social participation and self-perceived health among older people in transitional Kosovo. Eur J Public Health 2014; 24(2): 333-337. https://doi.org/10.1093/eurpub/ckt064.

9. McKnight M. Information prescriptions, 1930-2013: an international history and comprehensive review. J Med Libr Assoc 2014; 102(4): 271280. https://doi.org/10.3163/1536-5050.102.4.008.

10. Mettler M, Kemper DW. Information Therapy: the strategic role of prescribed information in disease self-management. International journal of rheumatic diseases 2005; 8(2): 69-76. https://doi.org/10.1111/j.1479-8077.2005.00132.x.

11. Rezaei Hachehsou $P$, Habibi S, Fozounkhah S. Information technology, an effective tool in reducing and preventing medical errors: Suggestions for improvement. Health Information Management 2007; 4(1): 89-98. Persian. http://him.mui.ac.ir/index.php/him/article/view/70.

12. National Heart Lung and Blood Institute. Bethesda: National Heart Lung and Blood Institute, Health Information Center. https://www.nhlbi.nih.gov/.

13. PlanTree Health information. United States: PlanTree Health information center about us. https://www. planetree-sv.org/.

14. The Health Information Resource Center at University of Washington Medical Center. https://www.uwmedicine.org/patient-resources/uwmedical-center-health-information-resource-center

15. Samadbeik M, Ebrahimi S, Kafashi M, Garavand A, Ghanbari S. Tele ECG; Applications, Infrastructures and Necessity of Using it. Journal of Health and Biomedical Informatics 2016; 2(4): 257-265. Persian. http://jhbmi.ir/article-1-111-en.html.

16. Shahrud University of Medical Sciences. The third meeting of the national Iranian cohort, 2016.Persian. http://www.shmu.ac.ir

17. Mettler M, Kemper DW. Information therapy: The strategic role of prescribed information in disease self-management. Stud Health Technol Inform 2006; 121: 373-383. https://pubmed.ncbi.nlm.nih.gov/17095835/.

18. Zarei A. An overview the topics of the rights and responsibilities of patients in health systems. Hamshahri, 2010. Persian. https://www.hamshahrionline.ir/news/21119.

19. Rezaeehachesoo P, Habibi Sh, Fozonkhah Sh. Information technology, an effective tool in reducing and preventing medical errors: suggestions for improvement. Health Information Management 2007; 4(1): 89-98. http://him.mui.ac.ir/index.php/him/article/view/70.

20. Gavgani VZ. Ubiquitous information therapy service through social networking libraries: an operational Web 2.0 service model. In: UserDriven Healthcare: Concepts, Methodologies, Tools, and Applications. Biswas R, Martin CM, eds. Pennsylvania: IGI Global, USA. 2011: 446461. https://doi.org/10.4018/978-1-60960-097-6.ch030.

21. Mitchell D J. Toward a definition of information therapy. Proc Annu Symp Comput Appl Med Care 1994: 71-75. https://www.ncbi.nlm.nih.gov/pmc/articles/PMC2247874/.

22. Burrington-Brown J. Information therapy: a new interest for HIM. https://library.ahima.org/doc?oid=91412.

23. PlaneTree Health Information Center at Cupertino Library. https://www.smc-connect.org/locations/planetree-healthinformation-center-at-cupertino-library.
24. National Heart Lung and Blood Institute. Health Information Center. https://health.gov/our-work/health-literacy/resources/nationalhealth-information-center/clearinghouses/topic

25. Global Health Resource Center. https://www.washington.edu/research/research-centers/globalhealth-resource-center/

26. Zeinali V, Riahinia N. Information therapy services in educational hospitals: a feasibility study in educational hospitals of Shahid Beheshti University of Medical Sciences. Journal of Health Administration 2015; 18(59): 66-81. Persian. http://jha.iums.ac.ir/article-1-1640-en.html

27. Gavgani VZ, Mahami M. The assessment of information prescription service to patients with heart valve disease; applying user's satisfaction study. Library Philosophy and Practice (e-journal) 2012; 862. https://digitalcommons.unl.edu/libphilprac/862.

28. Burke $M$, Carey $P$, Pond F, Haines L, Lampson A. Information Rx as Patient-Physician Communication Tool and Community Health Information Program. University Libraries Faculty and Staff Publications 2008; 24. https://scholarworks.uvm.edu/libfacpub/24.

29. Koonce TY, Giuse NB, Storrow AB. A pilot study to evaluate learning style-tailored information prescriptions for hypertensive emergency department patients. J Med Libr Assoc 2011; 99(4): 280-289. https://doi.org/10.3163/1536-5050.99.4.005.

30. Oliver KB, Lehmann HP, Wolff AC, Davidson LW, Donohue PK, Gilmore $\mathrm{MM}$, et al. Evaluating information prescriptions in two clinical environments. J Med Libr Assoc 2011; 99(3): 237-246. https://doi.org/10.3163/1536-5050.99.3.011.

31. Kinnane NA. Evaluation of a hospital-based cancer information and support centre. Support Care Cancer 2012; 20(2): 287-300. https://doi.org/10.1007/s00520-010-1071-y.

32. Rylance A. Using information prescriptions in diabetes. Nurs Times 2015; 111(10): 12-13. https://pubmed.ncbi.nlm.nih.gov/26285435/.

33. Timm DF, Jones D. The information prescription: Just what the doctor ordered! Journal of Hospital Librarianship 2011; 11(4): 358-365. https://doi.org/10.1080/15323269.2011.611110.

34. Zeinali V, Riahinia N, Javadi Parvaneh V, Asadi S. Effect of Health Information Prescription (HIP) on caregiver's self-care ability. Human Info Interact 2017; 4(1): 16-27. Persian. http://hii.khu.ac.ir/article-12696-en.html.

35. Ulmer PA, Robishaw S. Information prescriptions: providing health information at the inpatient's point of medical need. Journal of Consumer Health on the Internet 2010; 14(2): 138-149. https://doi.org/10.1080/15398281003781006.

36. Beaudoin DE, Longo N, Logan RA, Jones JP, Mitchell JA. Using information prescriptions to refer patients with metabolic conditions to the Genetics Home Reference website. J Med Libr Assoc 2011; 99(1): 70-76. https://doi.org/10.3163/1536-5050.99.1.012.

37. Coberly E, Boren SA, Mittal M, Davis JW, Scoville C, Chitima-Matsiga R, et al. MedlinePlus-based health information prescriptions: a comparison of email vs paper delivery. Inform Prim Care 2013; 20(3): 197-205. https://doi.org/10.14236/jhi.v20i3.25.

38. Rani NA, Hemavathy V. Information therapy. International Journal of Science and Research (IJSR) 2016; 5(1): 417-418. https://www.ijsr.net/get_abstract.php?paper id=20121502.

39. Colledge A, Car J, Donnelly A, Majeed A. Health information for patients: time to look beyond patient information leaflets. J $R$ Soc Med 2008; 101(9): 447-453. https://doi.org/10.1258/jrsm.2008.080149.

40. Siegel ER, Logan RA, Harnsberger RL, Cravedi K, Krause JA, Lyon B, et al. Information Rx: Evaluation of a new informatics tool for physicians, patients, and libraries. Inf Serv Use 2006; 26(1): 1-10. https://doi.org/10.3233/isu-2006-26101.

41. Burke M, Carey $P$, Haines L, Lampson AP, Pond F. Implementing the information prescription protocol in a family medicine practice: a case study. J Med Libr Assoc 2010; 98(3): 228 https://doi.org/10.3163/1536-5050.98.3.011. 
42. Gavgani VZ. Evidence based information prescription (Ips) in developing countries. In: Evidence Based Medicine-Closer to Patients or Scientists? Sitaras N, ed. Rijeka: IntechOpen, Croatia. 2012: 89-98. https://doi.org/10.5772/38238.

43. Khansa L, Davis Z, Davis H, Chin A, Irvine H, Nichols L, et al. Health information technologies for patients with diabetes. Technology in Society 2016; 44: 1-9. https://doi.org/10.1016/j.techsoc.2015.11.001.

44. Dillon K. "Health Information Prescription" Project Launched in $\begin{array}{lll}\text { Virginia. Virginia Libraries } & \text { 2004; }\end{array}$ https://doi.org/10.21061/valib.v50i1.928.

45. Sohrabi S. Information therapy and its role in health. In: The 2nd National Conference of Book \& Reading: Media \& Health. Tabriz: Tabriz University of Medical Sciences, Iran, 2016: 125-142. https://researchvice.tbzmed.ac.ir/

46. Gavgani VZ. Information therapy (Ix) service and patients' preference. International Journal of Computational Models and Algorithms in Medicine (IJCMAM) 2011; 2(2): 42-50. https://doi.org/10.4018/jcmam.2011040103.

47. Leisey MR, Shipman JP. Information prescriptions: a barrier to fulfillment. J Med Libr Assoc 2007; 95(4): 435-438. https://doi.org/10.3163/1536-5050.95.4.435.

48. Grant RW, Wald JS, Poon EG, Schnipper JL, Gandhi TK, Volk LA, et al. Design and implementation of a web-based patient portal linked to an ambulatory care electronic health record: patient gateway for diabetes collaborative care. Diabetes Technol Ther 2006; 8(5): 576-586. https://doi.org/10.1089/dia.2006.8.576.

49. Hand A, Greenwell K, Corbett S, Walker R, Kirrane H. Developing an information prescription service. Nurs Times 2008; 104(39): 34-37. https://pubmed.ncbi.nlm.nih.gov/19051547/.

50. Witman L. "Information Prescription" orders in the electronic medical record at UVA: Bringing our consumer health information service to the bedside and planning for outcomes research. Journal of Hospital Librarianship 2017; 17(2): 137-146. https://doi.org/10.1080/15323269.2017.1291049.

51. Sonika R, Sharma VL, Singh A. Information Therapy: Bridging the information gap between doctors and patients. South East Asia Journal of Public Health 2015; 4(2): 47-50. https://doi.org/10.3329/SEAJPH.V4I2.23695.

52. Andersen CM. Information therapy: a prescription for the digital era. The health care manager 2013; 32(3): 242-245. https://doi.org/10.1097/hcm.0b013e31829d766b.

53. Gurupur VP, Gutierrez R. Designing the right framework for healthcare decision support. Journal of Integrated Design and Process Science 2016; 20(1): 7-32. https://doi.org/10.3233/jid-2016-0001.

54. Oliver KB, Lehmann HP, Wolff AC, Davidson LW, Donohue PK, Gilmore $\mathrm{MM}$, et al. Evaluating information prescriptions in two clinical environments. J Med Libr Assoc 2011; 99(3): 237-246. https://doi.org/10.3163/1536-5050.99.3.011.

55. McShane L, Greenwell K, Corbett S, Walker R. Developing a long-term condition's information service in collaboration with third sector organizations. Health Info Libr J 2014; 31(2): 106-115. https://doi.org/10.1111/hir.12064.

56. Gavgani VZ. Role of librarians in information therapy (Ix): a comparative study of two developing countries. Aslib Proceedings 2011; 63(6): 603-617. https://doi.org/10.1108/00012531111187252.

57. Garnweidner-Holme LM, Borgen I, Garitano I, Noll J, Lukasse M. Designing and Developing a Mobile Smartphone Application for Women with Gestational Diabetes Mellitus Followed-Up at Diabetes Outpatient Clinics in Norway. Healthcare (Basel) 2015; 3(2): 310-323. https://doi.org/10.3390/healthcare3020310.

58. Pagels AA, Hylander B, Alvarsson M. A multi-dimensional support Programme for patients with diabetic kidney disease. J Ren Care 2015; 41(3): 187-194. https://doi.org/10.1111/jorc.12114

59. Ayanlade O, Oyebisi T, Kolawole B. Development of an ICT-based framework towards sustainable optimal diabetes management in
Nigerian health sector. Informatics in Medicine Unlocked. 2018; 11: 36 43. https://doi.org/10.1016/j.imu.2018.04.002.

60. Ahmad FS, Tsang T. Diabetes prevention, health information technology, and meaningful use: challenges and opportunities. Am J Prev Med 2013; 44(4): S357-S363. https://doi.org/10.1016/j.amepre.2012.12.020.

61. Brewster L, Sen B. 'Quality signposting': the role of online information prescription in providing patient information. Health Info Libr J 2011 28(1): 59-67. https://doi.org/10.1111/j.1471-1842.2010.00912.x.

62. Alirezaei Shahraki R, Aliakbari Kamrani A, Sahaf R, Abolfathi Momtaz Y Effects of Nationwide Program for Prevention and Control of Diabetes Initiated by the Ministry of Health on Elderly Diabetic Patients' Knowledge, Attitude and practice in Isfahan. Iranian Journal of Ageing 2019; 14(1): 84-95. https://doi.org/10.32598/SIJA.14.1.84.

63. Puustjärvi J, Puustjärvi L, editors. Exploiting Personal Health Records in automating information therapy. In: Second International Conference on eHealth, Telemedicine, and Social Medicine. St. Maarten: IEEE, Netherlands. 2010: 100-105. https://doi.org/10.1109/eTELEMED.2010.20.

64. Zare-Farashbandi F, Lalazaryan A, Rahimi A, Hasssanzadeh A. The effect of contextual factors on health information-seeking behavior of Isfahan diabetic patients. Journal of Hospital Librarianship 2016; 16(1): 1-13. https://doi.org/10.1080/15323269.2016.1118266.

65. Chamberlain D, Heaps D, Robert I. Bibliotherapy and information prescriptions: a summary of the published evidence-base and recommendations from past and ongoing Books on Prescription projects. J Psychiatr Ment Health Nurs 2008; 15(1): 24-36. https://doi.org/10.1111/i.1365-2850.2007.01201.x.

66. Bond $\mathrm{CS}$, Ahmed $\mathrm{OH}$. Can I help you? Information sharing in online discussion forums by people living with a long-term condition. J Innov Health Inform 2016; 23(3): 620-626. http://dx.doi.org/10.14236/jhi.v23i3.853.

67. Zahanova S, Tsouka A, Palmert MR, Mahmud FH. The iSCREEN electronic diabetes dashboard: a tool to improve knowledge and implementation of pediatric clinical practice guidelines. Can J Diabetes 2017; 41(6): 603-612. https://doi.org/10.1016/i.jcjd.2016.12.012.

68. Doshi R. Information Prescription and Information Therapy: Practicing Medicine in the Information Age. International Journal of User-Driven Healthcare (IJUDH) 2013; 3(2): 85-87. https://doi.org/10.4018/ijudh.2013040110.

69. Cunningham SG, Wake DJ, Waller A, Morris AD, Walker J. My Diabetes My Way: an electronic personal health record for diabetes. The British Journal of Diabetes \& Vascular Disease 2013; 13(3): 143-149. https://doi.org/10.1177/1474651413493336.

70. Mazzi CP, Kidd M. A framework for the evaluation of Internet-based diabetes management. J Med Internet Res 2002; 4(1): e1. https://doi.org/10.2196/jmir.4.1.e1.

71. Brady E, Segar J, Sanders C. Accessing support and empowerment online: The experiences of individuals with diabetes. Health Expect 2017; 20(5): 1088-1095. https://doi.org/10.1111/hex.12552.

72. Aanestad M, Grisot M, Hanseth O, Vassilakopoulou P. Information infrastructures for eHealth. In: Information Infrastructures within European Health Care. Aanestad M, Grisot M, Hanseth O, Vassilakopoulou P, eds. Cham: Springer International Publishing, Switzerland. 2017: 11-23. https://doi.org/10.1007/978-3-319-51020-0.

73. Gavgani VZ, Shiramin AR. Physician directed information prescription service (IPs): barriers and drivers. Aslib Proceedings 2013; 65(3): $224-$ 241. https://doi.org/10.1108/00012531311330629.

74. Du HS, Ma JJ, Li M. High-quality health information provision for stroke patients. Chin Med J (Engl) 2016; 129(17): 2115-2122. https://doi.org/10.4103/0366-6999.189065.

75. Petrovski G, Zivkovic M, Stratrova SS. Social media and diabetes: can Facebook and Skype improve glucose control in patients with type 1 diabetes on pump therapy? One-year experience. Diabetes care 2015; 38(4): e51-e52. https://doi.org/10.2337/dc14-2487. 
76. Yarahmadi A, Zare-Farashbandi F, Kachuei A, Nouri R, Hassanzadeh A. The effects of non-attendance information therapy on the control of glycosylated hemoglobin $(\mathrm{HbA} 1 \mathrm{C})$ in type 2 diabetic patients. J Educ Health Promot 2014; 3: 90. https://doi.org/10.4103/22779531.139650.

77. Boyer C, Dolamic L. Feasibility of automated detection of HONcode conformity for health-related websites. International Journal of Advanced Computer Science and Applications (IJACSA) 2014; 5(3): 6974. https://doi.org/10.14569/IJACSA.2014.050309.

78. O'keefe LP. Health information prescription. General Electric Company. United States patent application, 2015. US 14/091,881. https://patentimages.storage.googleapis.com/c2/82/e5/c584c2c422ce cc/US20150149207A1.pdf.

79. Firooz M, Hoseini SJ, Mazlom SR, Hasanzadeh F, Kimiaie SA. Self-care of Patient with Diabetes Type II. Journal of Sabzevar University of Medical Sciences 2016; 22(6): 1018-1025. Persian. http://jsums.medsab.ac.ir/article_786_en.html.

80. Tara M. Aspects of Information Tailoring in the 21st Century. In: Encyclopedia of Information Science and Technology, Third Edition. Hershey: IGI Global, USA. 2015: 4042-4052. https://doi.org/10.4018/978-1-4666-5888-2.

81. Joshy G, Simmons D. Diabetes information systems: a rapidly emerging support for diabetes surveillance and care. Diabetes Technol Ther 2006; 8(5): 587-597. https://doi.org/10.1089/dia.2006.8.587.

Authors:

Abdolahad Nabiolahi - Phd Candidate, Department of Medical Library and Information Sciences, School of Health Management \& Information Sciences, Iran University of Medical Sciences, Tehran, Iran. https://orcid.org/0000-0001-8897-6451.

Shahram Sedghi - PhD, Professor, Health Management and Economics Research Center, Iran University of Medical Sciences, Tehran, Iran; Librarianship and Medical Information Science Department, Iran University of Medical Sciences, Tehran, Iran. https://orcid.org/0000-0001-6457-7464.

Rokhsareh Aghili - MD, Assistant Professor, Endocrine Research Center, Institute of Endocrinology and Metabolism, Iran University of Medical Sciences, Tehran, Iran. https://orcid.org/0000-0002-5272-0136.

Leila Nemati-Anaraki - PhD, Assistant Professor, Department of Medical Library and Information Sciences, Iran University of Medical Sciences, Tehran, Iran; Health Management and Economics Research Center, Iran University of Medical Sciences, Tehran, Iran. https://orcid.org/0000-00029436-2533. 


\begin{tabular}{|c|c|c|c|c|}
\hline Author's Name & Year & Study design & Research Setting & Subjects \\
\hline Zeinali V, Riahinia N & 2015 & Quantitative/Descriptive & $\begin{array}{l}\text { Iran, Shahid Bchcshti University of } \\
\text { Medical }\end{array}$ & Sciences Information Prescription System Axes \\
\hline $\begin{array}{l}\text { Zeinali V, Riahinia N } \\
\text { Vadood Javadi p, Asadi S [34] }\end{array}$ & 2017 & $\begin{array}{l}\text { Quantitative/Quasi- } \\
\text { Expcrimcnlal }\end{array}$ & Iran,Mofid Children Medical Center & Information Prescription System advantages \\
\hline Mettler M, Kemper D [21] & .2003 & Review & United States & Factors affecting Information Prescription System \\
\hline Zarea Gavgani V & 2011 & Review & Iran & $\begin{array}{c}\text { Elements of Health Information Prescription } \\
\text { System }\end{array}$ \\
\hline Zarci Farashbandi $F$, Yarahmadi $A[1]$ & 2015 & Review & Iran & Substructures of Information Prescription System \\
\hline Andersen CM [52] & 2013 & Review & Kentukey uni & $\begin{array}{l}\text { Definition of Information Prescription and } \\
\text { Strategies of System Development }\end{array}$ \\
\hline Zarea Gavgani V [27] & 2012 & Quantitative & Iran. Tabriz Shahid Madani Hospitaljran & Dimensions of Information Prescription System \\
\hline Timin DF, Jones D [33] & 2011 & Review & United States & $\begin{array}{c}\text { System Goals and Information Prescription } \\
\text { Sending Process }\end{array}$ \\
\hline Zarea Gavgani V $|46|$ & 2013 & Quantitative & Iran, Tabriz University of Medical Sciences & Modifiers of Information Prescription System \\
\hline Ülmer P, Robishaw S [35] & 2010 & Quantitative/Survey & United States, State of Pennsylvania & Modifiers Information Prescription System Health \\
\hline Mettler M, Kemper D [10] & 2005 & Review & United States & Modifiers of Information Prescription System \\
\hline Siegel $E$, et al $|40|$ & 2006 & Qjiantitative/Survey & United States & Information Prescription System advantages \\
\hline Hand A, et al [49] & 2015 & $\begin{array}{l}\text { Mixed (Quantitative \& } \\
\text { Qualilativc) }\end{array}$ & United Kingdom & Dimensions of Information Prescription System \\
\hline Rylance A [32] & 2018 & Review & United Kingdom & $\begin{array}{c}\begin{array}{c}\text { Different Dimensions of Information Prescription } \\
\text { System }\end{array}\end{array}$ \\
\hline Coberly E. et al [37] & 2012 & Quantitative/ RCT & United Slates & $\begin{array}{l}\text { Assessment of I lealth Information System } \\
\text { Mechanism (System accessibility) }\end{array}$ \\
\hline Du HS, Ma JJ, Li M & 2016 & Review & China & $\begin{array}{l}\text { Different Methods of Sending } 1 \text { lealth } \\
\text { Information (access ability) }\end{array}$ \\
\hline Gavgani VZ, Mahami M & 2012 & $\begin{array}{l}\text { Quantitative (Cross- } \\
\text { Sectional) }\end{array}$ & Tran & $\begin{array}{l}\text { Assessment of Health Information System } \\
\text { Effectiveness System (accessibility) }\end{array}$ \\
\hline Burke, et al & 2010 & Quantitative/Survey & United States & $\begin{array}{l}\text { Assessment of Health Information System Impact } \\
\text { ( accessibility) }\end{array}$ \\
\hline Brewster L, Sen B & 2010 & Conipcrativc & United Kingdom & Dimensions of Information Prescription System \\
\hline Ayanlade OS & 2018 & $\begin{array}{l}\text { Mixed (Quantitative } \\
\text { \&Qualilative) }\end{array}$ & Nigeria & Information Prescription Successfulness \\
\hline Brady & 2017 & $\begin{array}{l}\text { Qualitative Semi- } \\
\text { structured }\end{array}$ & United Kingdom & Use of Online Information Sending Mechanism \\
\hline Firozeh Zareh & 2015 & Quantitative/ Survey & Tran & $\begin{array}{l}\text { Information Behavior Recognition of Users with } \\
\text { diabetes Patients }\end{array}$ \\
\hline Varadraj P Gurupur & 2016 & Review & United States & Essential elements of Decision Support System \\
\hline Sharaki Alireza & 2019 & Quantitative/ Survey & Iran & $\begin{array}{l}\text { Patients' Family and Health Services Team } \\
\text { Participation in Information Prescription }\end{array}$ \\
\hline Khansa I, et al & 2015 & Qualitative/ & United States & Barriers of Using System \\
\hline Faras A \& Tsang T & 2013 & a brief overview & & Strategies, Challenges and System Opportunities \\
\hline Kinannc NA & 2011 & Quantitative /Survey & Australia & $\begin{array}{l}\text { Recognition and responding Patient's } \\
\text { Informational Needs by Now Technology }\end{array}$ \\
\hline Macknighl M & 2014 & Review & United States & Different Dimensions of Information Prescription \\
\hline D'Alessandro DM & 2004 & Quantitative/ RCT & iowa & Internet Use for Information Prescription \\
\hline Koonce $\mathrm{T}$, et al & 2015 & Quantitative/ RCT & United Stales & $\begin{array}{c}\text { Effectiveness of Personalized Health Information } \\
\text { Prescription }\end{array}$ \\
\hline Coberly, et al & 2010 & Quantitative/ RCT & United States & $\begin{array}{c}\text { Establishment Strategy of Health Information } \\
\text { Prescription System }\end{array}$ \\
\hline Beaudoin DE & 2011 & Quantitative/ Survey & United States & Health Information Prescription Effectiveness \\
\hline Schneider & 2005 & Practical Expcrinccs IPS & United States & $\begin{array}{l}\text { Role of Collaborative Team especially in } \\
\text { Information Prescription }\end{array}$ \\
\hline Witman & 2005 & Practical Expeiinces IPS & United States & $\begin{array}{l}\text { Use of Electronic Medical Chart in Health } \\
\text { Information Prescription }\end{array}$ \\
\hline Puustjarvi & 2010 & Review & Finland & Personal health records role in TPS \\
\hline Karn dillon & 2004 & Practical Experinces IPS & United States & Dimensions of Information Prescription System \\
\hline Chamberlain D & 2008 & Review & United Kingdom & Dimensions of Health Information Prescription \\
\hline Rani NA, Hemavathy V & 2014 & Review & India & $\begin{array}{l}\text { Goals, Strategies and Barners of Health } \\
\text { Information Prescription System }\end{array}$ \\
\hline Leisy M & 2007 & Qualitative & United States & Recognition of Barners against Information \\
\hline
\end{tabular}




\begin{tabular}{|c|c|c|c|c|}
\hline Author's Name & Year & Study design & Research Setting & Subjects \\
\hline & & & & Prescription Establishment \\
\hline Colledge A. & 2008 & Review & United Kingdom & $\begin{array}{l}\text { Development Strategy of Information } \\
\text { Prescription System (The Comparison of Text or } \\
\text { Brochure with other References) }\end{array}$ \\
\hline Sonika G, et al & 2014 & Review & India & $\begin{array}{l}\text { Goals, Strategies and Barriers of Health } \\
\text { Information Prescription System }\end{array}$ \\
\hline Garnweidner- Holme & 2015 & Qualitative & Norway & Design, Content and Function of the System \\
\hline Cunningham SG & 2013 & $\begin{array}{l}\text { Quantitative/ Quaxi- } \\
\text { exprimental }\end{array}$ & United Kingdom /Scotland & $\begin{array}{l}\text { System Dimensions: Personal electronic Health } \\
\text { Chart }\end{array}$ \\
\hline Bond C \& Ahmed HO & 2016 & Qualitative & United Kingdom & $\begin{array}{l}\text { Used Approaches for Directing the Peer patients } \\
\text { to information References }\end{array}$ \\
\hline Oliver, et al & 2011 & Quantitative/ RCT & United States & $\begin{array}{c}\text { Information Prescription Effectiveness and } \\
\text { Problems }\end{array}$ \\
\hline Zahanova S & 2016 & Quantitative/ Survey & Canada & $\begin{array}{c}\text { Effectiveness of Decision support System Based } \\
\text { on Patient's Knowledge }\end{array}$ \\
\hline Meeks K & 2009 & $\begin{array}{l}\text { Mixed (Survey \& } \\
\text { interview) }\end{array}$ & United States & $\begin{array}{l}\text { Contribution of Physicians and Librarians in } \\
\text { Information Prescription Program }\end{array}$ \\
\hline Joshy G & 2006 & Review & New Zealand & $\begin{array}{l}\text { Succcssfidncss Dimensions of Diabetic } \\
\text { Information System }\end{array}$ \\
\hline Lester WT & 2008 & Review/Analytical & United States & Design Strategies of Diabetes Information system \\
\hline Mcshane, et al & 2014 & Quantitative & United Kingdom & $\begin{array}{l}\text { Public Organization Contribution in Dimensions of } \\
\text { Information Prescription System }\end{array}$ \\
\hline Grant Rw, et al & 2006 & Mixed & United States & $\begin{array}{l}\text { Dimensions of Supporting System Provided for } \\
\text { Diabetic Patients }\end{array}$ \\
\hline Rillcrband LM, et al & 2005 & Quantitative & United States & $\begin{array}{l}\text { Dimensions of Information Prescription System } \\
\text { Tools and Barriers of its Use }\end{array}$ \\
\hline Mazzi C \& Kidd M & 2002 & $\begin{array}{l}\text { Qualitative/ Framework } \\
\text { Analysis }\end{array}$ & Australia & Modifiers of Diabetes Information System \\
\hline Doshi R & 2013 & Review & United States & $\begin{array}{l}\text { Concepts of Dimensions of Information } \\
\text { Prescription System and its Use in Medicine }\end{array}$ \\
\hline
\end{tabular}

